\title{
Leverage vs. Feedback: Which Effect Drives the Oil Market?
}

\author{
Sofiane Aboura* and Julien Chevallier ${ }^{\dagger}$
}

July 23, 2012

\begin{abstract}
This article brings new insights on the role played by (implied) volatility on the WTI crude oil spot price. An increase in the volatility subsequent to an increase in the oil price (i.e. inverse leverage effect) remains the dominant effect as it might reflect the fear of oil consumers to face rising oil prices. However, this effect is amplified by an increase in the oil price subsequent to an increase in the volatility (i.e. inverse feedback effect) with a two-day delayed effect. This lead-lag relation between the oil price and its volatility is determinant for any type of trading strategy based on futures and options on the OVX implied volatility index, and thus is of interest to traders, risk- and fund-managers.
\end{abstract}

Keywords: WTI, Crude Oil Price, Implied Volatility, Leverage Effect, Feedback Effect. JEL Codes: C4, G1, Q4.

\section{Introduction}

The rise of the US benchmark oil West Texas Intermediate (WTI) to 145 USD per barrel on July 3, 2008 and its collapse to below 30 USD per barrel on December 23, 2008 represents the biggest swing in the history of oil. This fact shows that the oil market exhibits a tail risk characteristic that is typically higher than for the stock market. This greater risk motivates the analysis of the oil volatility characteristic as a possible driver of oil prices.

Volatility is known to be asymmetric on equity markets due to two concomitant phenomena known as:

1. the so-called 'leverage effect' characterized by a surge in the volatility, subsequent to a drop in the stock price (see e.g. Black (1976) and Christie (1982)), and

2. the so-called 'feedback effect' which means that the causality can be reversed. If volatility is priced by market participants, an anticipated increase in volatility would raise the required rate of return on equity, which leads to a current stock price decline (see e.g. Campbell and Hentschel (1992) and Bekaert and $\mathrm{Wu}(2000)$ ). Indeed, volatility is asymmetric because the feedback effect amplifies negative stock returns. These studies seem to favor the feedback effect as the dominant factor explaining the asymmetric nature of volatility.

${ }^{*}$ DRM Finance (CEREG), University Paris Dauphine, Place du Maréchal de Lattre de Tassigny, 75775 Paris Cedex 16, France. Email: sofiane.aboura@dauphine.fr

${ }^{\dagger}$ Corresponding author. CGEMP/LEDa, University Paris Dauphine, Place du Maréchal de Lattre de Tassigny, 75775 Paris Cedex 16, France. Tel: +33(0)144054464. Fax: +33(0)144054484. Email: julien.chevallier@dauphine.fr 
However, contrary to equity markets, oil volatility seems to be positively correlated with past oil prices moves. While Geman and Shih (2009) have undoubtedly documented the existence of this inverse leverage effect in WTI prices, the authors mainly focus on the diffusion processes and neglect the identification of feedback effects. The same comment arises for the recent literature in energy economics (Agnolucci (2009), Larsson and Nossman (2011), Chang (2012)). In these contributions, the authors typically estimate various asymmetric GARCH models to take into account the inverse leverage effect in WTI prices, without a discussion on the feedback effects. Other authors have focused on the dynamic conditional correlations in WTI futures (see Lanza et al.(2006)).

The originality of this article stems from the fact that previous literature has neglected the investigation of leverage and feedback effects in WTI prices - the world's most liquid commodity futures - while these effects have been investigated in-depth on equity markets. Hence, we aim at filling this gap. We formally test for the presence of feedback and leverage effects in the volatility of WTI prices by running OLS regressions in the spirit of Hibbert et al. (2008) and Fleming et al. (1995). To do so, this article uses an index of implied volatility applied to the oil market (equivalent to the VIX methodology) given that the asymmetry is stronger for implied volatility than for historical volatility (see e.g. Bollerslev and Zhu (2006)). Our study period goes from May 2007 to December 2011.

As a proxy for the Implied Volatility (IV) of the WTI price, we use the CBOE Crude Oil ETF Volatility Index ('Oil VIX', Ticker - OVX). The OVX measures the market's expectation of 30-day volatility of crude oil prices by applying the VIX methodology to United States Oil Fund, LP (Ticker - USO) options spanning a wide range of strike prices. In previous studies (Agnolucci (2009), Larsson and Nossman (2011)), actual option prices were used to obtain the Black-Scholes implied volatility. To our best knowledge, this article is the first to make use of the CBOE OVX index. These CBOE indices based on the VIX methodology have been mainly used for equities (see Konstantinidi et al. (2008) for a recent contribution).

For the purpose of the econometric analysis, this article employs two additional volatility series. First, we extract the conditional volatility of the WTI spot price from an ARMA(1,1)-GARCH $(1,1)$ model (following the examination of 25 competing GARCH models) as a proxy for the historical volatility. Second, we use intraday data on WTI futures prices contracts to obtain the realized volatility from the sum of intraday squared returns. The former time series is used to construct standardized returns, while the latter is used for robustness checks. Finally, we distinguish several sub-periods following the detection of structural breaks in the OVX index.

The article is organized as follows. Section 2 presents an analysis of the data. Section 3 opens with the methodology employed, while section 4 analyses the empirical results. Section 5 summarizes the main findings and concludes.

\section{Data analysis}

This section details (i) the data used, (ii) the filtering process to extract the historical GARCH volatility, (iii) the construction of the realized volatility, and (iv) structural break tests to detect instability in the Implied volatility series.

\subsection{Data description}

The database consists of 1,172 crude oil WTI Cushing daily spot closing prices and CBOE OVX Index spanning the period of time going from May 10, 2007 to December 30, 2011. The dataset 
starts at the beginning of the availability of the OVX index, as provided by the CBOE. Hence, our dataset corresponds to the most recent period of WTI price variation, characterized by the 2008 oil price swing.

\section{Insert Figure 1}

Figure 1 plots the time series of raw WTI prices (solid black line), and the CBOE OVX Index (dotted black line $)^{1}$. Various regimes are visible, where price and volatility seem to be either positively or negatively correlated. During extreme periods of price and volatility, there seems to appear a negative correlation since (i) when the volatility peaks at $100.42 \%$ on December 11 2008, the corresponding WTI price per barrel is only $47.77 \$$, and (ii) when the WTI price peaks at $145.31 \$$ on July 32008 , the implied volatility declined to $44.39 \%$. This requires distinguishing among volatility regimes (calm and turbulent). The gray rectangle represents the financial crisis period as discussed in Section 2.4.

\section{Insert Table 1}

Table 1 shows excess skewness and kurtosis with a strong rejection of the normality hypothesis for all series. Non reported correlogram for the WTI residuals exhibits no more dependence since the $Q$-statistics for the series are lower than the critical values. The Engle's Lagrange multiplier test statistic shows no more evidence of remaining $\mathrm{ARCH}$ effects.

\subsection{Data filtering process}

The study tests 25 specifications of $\operatorname{ARMA}(p, q)+\operatorname{GARCH}(p, q)$ models with $p=1, \ldots, 5$ and $q=$ $1, \ldots, 5$. The selection favors the most parsimonious model given four criteria used for comparison: the log-likelihood value, the Akaike criterion, the autocorrelogram of residuals and squared residuals, and the Engle-ARCH test. The $\operatorname{ARMA}(1,1)+\operatorname{GARCH}(1,1)$ model produces the best fit. An alternative model allowing for leverage effects was considered to evaluate the contribution of the negative residuals in the $\mathrm{ARCH}$ effect. However, this $\operatorname{ARMA}(1,1)+\mathrm{TGARCH}(1,1)$ model yields a threshold parameter that is not statistically significant. These results are not reproduced in the article to conserve space, but are available upon request.

Define the market log-returns as $\left\{R_{t}\right\}_{t=1, \ldots, T}$ with $\mathrm{T}=1,172$ daily observations. The $\operatorname{ARMA}(1,1)$ $+\operatorname{GARCH}(1,1)$ specification is then given as follows:

$$
R_{t}=\mu+\phi_{1} R_{t-1}+\theta_{1} \epsilon_{t-1}+\epsilon_{t}
$$

where the innovations $\epsilon_{t}$ being functions of $Z_{t}$ and $\sigma_{t}$ :

$$
\epsilon_{t}=Z_{t} \sigma_{t}
$$

with the standardized log-returns $Z_{t}$ are independent and identically distributed, such as:

$$
Z_{t} \hookrightarrow F_{Z}(0,1)
$$

\footnotetext{
${ }^{1}$ The graph of the historical GARCH and realized volatilities series is available upon request. July 2008-July 2009 corresponds to a period of high variability in both volatility series.
} 
where $F_{Z}$ is an unknown distribution of $Z$. The purpose of the time-varying $\sigma_{t}$ is to capture as much as possible of the conditional variance in the residual $\epsilon_{t}$ in order to leave $Z_{t}$ approximately independently and identically distributed:

$$
\sigma_{t}^{2}=\omega+\alpha\left(Z_{t-1} \sigma_{t-1}\right)^{2}+\beta \sigma_{t-1}^{2}
$$

The results for the maximum likelihood estimation of this model are displayed in the last column of Table 1. This model provides a very good fit according to the selected criteria, and all the parameters are highly statistically significant. We therefore extract the standardized returns $\left\{Z_{t}\right\}_{t=1, \ldots, T}$ using a time-varying volatility model. The discussion is hereafter restricted to the standardized returns maxima $+Z$ and minima $-Z$.

\subsection{Realized volatility}

In addition to daily data, intraday data was purchased from TickData for the WTI light sweet crude oil futures contract. As is usual, we consider the continuous series of the front month contract using a rollover procedure which selects the largest volume each day to jump from one contract to the next ${ }^{2}$.

We choose to work with open-to-close returns because overnight returns have shown to follow a very different dynamics. In addition, including overnight returns may alter our analysis when standardizing returns as we work with volatility computed with intraday transaction data.

The total number of ticks for the continuous time series of the front month contract is equal to 16,941,854. The trading period for the WTI futures is from 9:00 AM to 2:30 PM, which should provide 60 intraday returns each day. The cleaning procedure involves removing days with less than 60 intraday returns, days with more than 15 zero-returns, and days with less than 700 registered ticks.

According to Andersen et al. (2003), the realized volatility (RV) is defined as the sum of returns at a frequency $1 / \Delta$ (typically one-day horizon), or:

$$
R V_{t+1}(\Delta) \equiv \sum_{j=1}^{1 / \Delta} R_{t+j . \Delta, \Delta}^{2}
$$

Finally, note that the time series of realized volatility has been constructed with a sampling frequency of 5-minute returns. As WTI futures are highly liquid assets, this sampling interval corresponds to standard practice to minimize the impact of microstructure noise. This time series will be used in the robustness checks of our econometric analysis.

\subsection{Breakpoints detection}

The second stage of the analysis consists in detecting structural breaks. They occur in a time series when the structure of the data generating mechanism underlying a set of observations changes. The detection of structural breaks in the volatility series allows to identify sub-periods, which will be useful during the robustness checks of our results.

\footnotetext{
${ }^{2}$ We do not build our continuous series using a fixed number of days prior to maturity, thus avoiding calendar effects.
} 
Bai and Perron $(1997,1998,2003)$ have developed very popular techniques to estimate and test linear models with multiple structural changes. By borrowing notations from Zeileis and Kleiber (2005), we briefly recall below the multiple linear regression model with $m$ breaks (or, equivalently, $m+1$ regimes):

$$
y_{t}=x_{t}^{\top} \delta_{j}+u_{t}, \quad t=T_{j-1}+1, \ldots, T_{j}, \quad j=1, \ldots, m+1
$$

with $T$ the sample size, $T_{0}=0$ and $T_{m+1}=T$. The goal of the analysis is to determine the number and location of the breakpoints $T_{j}, j=1, \ldots, m$. A search over $m$ is conducted, for $m \leq m^{*}$, where $m^{*}$ is fixed by the researcher. The minimum number of observations per segment, $h$, can also be exogenously set by the user ${ }^{3}$.

In our setting, we have the OVX at hand for the WTI (from the VIX methodology based on option prices $)^{4}$. The procedure of breakpoints detection unfolds as follows. First, we specify a linear model in which the dependent variable (i.e. OVX) is modelled by just an intercept, and $h$ is set equal to 30. Second, the estimation output (not reproduced here because of its length) comprises a triangular matrix containing the residual sums of squares (RSS), the extraction of breakpoints, and the corresponding information criteria, coefficient estimates and confidence intervals as described by Bai and Perron. Third, we plot all models for a maximum of $m=1, \ldots, 37$ breaks along with the corresponding values of the Bayesian Information Criterion (BIC) and the RSS.

\section{Insert Figure 2}

In Figure 2, we observe that the BIC selects two breaks $m=2$ for OVX, and that the decrease of the RSS when passing from a two break to a three break model is significant. These results may be summarized as pointing to two competing models: $m=2$ or $m=3$. However, because information criteria are often downward-biased, Bai and Perron argue in favor of the presence of an additional break. That is why we proceed with the estimation of a three-break model for OVX.

The output (not shown here) returns coefficient estimates with standard errors utilizing a kernel heteroskedasticity and autocorrelation consistent (HAC) estimator ${ }^{5}$. We are also able to compute the confidence intervals (at the default $95 \%$ level) for the three breakpoints ${ }^{6}$.

The estimated breakpoints are for OVX:

1. March 6, 2008

2. October 2, 2008

3. April 15, 2009

\footnotetext{
${ }^{3}$ Note this may be considered as a bandwidth or trimming parameter.

${ }^{4}$ The same procedure of breakpoints detection has been applied to the historical volatility extracted from the GARCH model. The resuls are qualitatively similar, and are available upon request.

${ }^{5}$ With a quadratic spectral kernel, prewhitening using a $\operatorname{VAR}(1)$ model and an $\operatorname{AR}(1)$ approximation for the automatic bandwidth selection (see Zeileis and Kleiber (2005)).

${ }^{6}$ The confidence intervals are derived from the distribution of the argmax functional of a process composed of two independent Brownian motions with different linear drifts and scales (see Bai and Perron (1997) for further details on this nonstandard distribution). This cumulative distribution function depends on three parameters which are associated with ratios of quadratic forms in the magnitude of the shifts and weighting matrices defined as segmentwise covariance matrices (Zeileis and Kleiber (2005)).
} 
There is little variation ( 7 to 30 days) in the confidence intervals ${ }^{7}$ corresponding to the break dates. Hence, we obtain considerable certainty as to the location of the three breaks for OVX.

Overall, the breakpoints identified in the OVX volatility series point towards the definition of four sub-periods:

1. Sub-period \#1 (S1 = 207 observations): [May 10, 2007 - March 6, 2008]

2. $\underline{\text { Sub-period \#2 }}(\mathrm{S} 2=148$ observations): [March 7, 2008 - October 2, 2008]

3. Sub-period \#3 (S3 = 135 observations): [October 3, 2008- April 15, 2009]

4. $\underline{\text { Sub-period \#4 }}(\mathrm{S} 4=681$ observations): [April 16, 2009 - December 30, 2011]

The Sub-period \#1 corresponds to the trend of rising WTI prices. The Sub-period \#2 corresponds to the period of time during which WTI prices have been characterized by a strong surge followed by a dramatic correction. The Sub-periods \#3 and \#4 capture two different dynamics, respectively near the end of the WTI price correction and after April 15, 2009 when the effect of the WTI oil price swing seems to disappear. This information will be re-used in Section 4 for robustness checks. The main sub-period of interest is therefore S3 (which roughly goes from the Lehman-Brothers bankruptcy to the end of the recession according to the NBER Business Cycle Dating Committee). It has been represented in Figure 1 with a gray rectangle.

Next, we proceed with our econometric investigation of the leverage and feedback effects in these volatility series.

\section{Methodology}

Our econometric methodology is mainly based on two articles to test for the presence of leverage and feedback effects in the volatility of WTI spot prices. Concerning leverage effects, we follow the approach by Hibbert et al. (2008), who test various hypotheses of return-volatility relation with ordinary least squares (OLS). Contrary to them, this study does not make use of raw returns but standardized returns in order to neutralize the role of volatility in the return generating process. Concerning feedback effects, we follow the approach initiated by Fleming et al. (1995). In what follows, these two methodologies are presented in details.

For the leverage effect, the analysis is based on two sets of models labelled $M 1$ and $M 2$ :

- $M 1$ tests whether oil contemporaneous returns, oil lagged returns, and the absolute value of returns explain the current implied volatility log-changes.

$$
M 1: \Delta \log O V X_{t}=\alpha_{0}+\alpha_{1} Z_{t}+\alpha_{2} Z_{t-1}+\alpha_{3} \Delta \log O V X_{t-1}+\alpha_{4}\left|Z_{t}\right|+\alpha_{5} \epsilon_{t-1}+\epsilon_{t}
$$

with $\Delta \log O V X_{t}$ the log-variation of the OVX index, $\alpha_{0}$ the intercept, $Z_{t}$ standardized returns on the WTI prices, $Z_{t-1}$ standardized returns lagged one period, $\left|Z_{t}\right|$ the absolute value of the standardized returns, $\Delta \log O V X_{t-1}$ the $\mathrm{AR}(1)$ component, $\epsilon_{t-1}$ the $\mathrm{MA}(1)$ component, and $\epsilon_{t}$ the error term. The $\mathrm{AR}(1)-\mathrm{MA}(1)$ process has been specified following the Box-Jenkins methodology.

\footnotetext{
${ }^{7}$ Available upon request.
} 
- $M 2$ introduces two dummy variables to decompose the impact of lagged returns in positive $Z_{t-1}^{+}$and negative $Z_{t-1}^{-}$impacts.

$$
\text { M2: } \Delta \log O V X_{t}=\alpha_{0}+\alpha_{1} Z_{t}+\alpha_{2} Z_{t-1}^{+}+\alpha_{3} Z_{t-1}^{-}+\alpha_{4} \Delta \log O V X_{t-1}+\alpha_{5}\left|Z_{t}\right|+\alpha_{6} \epsilon_{t-1}+\epsilon_{t}
$$

Hence, $Z_{t-1}^{+}$and $Z_{t-1}^{-}$replace the influence of $Z_{t-1}$ in the former model.

For the feedback effect, the analysis is based on two sets of models labelled $M 3$ and $M 4$ :

- M3 tests whether contemporaneous implied volatility log-changes, lagged implied volatility log-changes, and the absolute value of implied volatility log-changes explain the current oil standardized returns.

$$
\begin{aligned}
\text { M3: } Z_{t}= & \alpha_{0}+\alpha_{1} \Delta \log O V X_{t}+\alpha_{2} \Delta \log O V X_{t-1}+\alpha_{3} \Delta \log O V X_{t-2}+\alpha_{4} \Delta \log O V X_{t-3} \\
& +\alpha_{5}\left|\Delta \log O V X_{t}\right|+\epsilon_{t}
\end{aligned}
$$

with $\Delta \log O V X_{t-1}$ to $\Delta \log O V X_{t-3}$ lagged values of the OVX index log-changes up to three days, and $\left|\Delta \log O V X_{t}\right|$ the absolute value of contemporaneous implied volatility log-changes.

- M4 introduces two dummy variables to decompose the impact of lagged implied volatility log-changes in positive $\Delta \log O V X_{t-1}^{+}$and negative $\Delta \log O V X_{t-1}^{-}$impacts.

$$
M_{4}: Z_{t}=\alpha_{0}+\alpha_{1} \Delta \log O V X_{t}+\alpha_{2} \Delta \log O V X_{t-1}^{+}+\alpha_{3} \Delta \log O V X_{t-1}^{-}+\alpha_{4}\left|\Delta \log O V X_{t}\right|+\epsilon_{t}
$$

Taken together, models $M 1$ to $M 4$ allow to test explicitly for the presence of leverage and feedback effects in the volatility of WTI spot prices.

\section{Results}

In what follows, estimation results are presented and analyzed. Besides, we discuss some measures used as robustness checks.

\subsection{Empirical results}

\section{Insert Table 2}

Insert Table 3

Tables 2 and 3 display the results respectively from models $\{M 1, M 2\}$ and $\{M 3, M 4\}$. By looking at the overall levels of the adjusted R-squared, the sets of regressions in the models $\{M 1, M 2\}$ appear more satisfactory than for the models $\{M 3, M 4\}$. Both tables show that the contemporaneous returns and volatility are negatively correlated, as judged by the $\alpha_{1}$ parameter for $Z_{t}$. In addition, the size effect parameter (i.e. absolute values) remains statistically significant, showing that the dependent variable is sensitive to the magnitude of shocks on the crude oil market. 
Table 2 reveals for model M1 that the $\alpha_{2}$ coefficient for one-day lagged standardized returns $Z_{t-1}$ are positive and statistically significant at the $1 \%$ level during the full period, which characterizes the so-called 'inverse leverage effect' (i.e. that volatility is increasing following increasing returns). This effect was documented on the crude oil market by Geman and Shih (2009), among others, and we are able to confirm its existence with the OVX index. This stylized fact is significant in only the first sub-period, because of the turbulent nature of the overall period with various regime changes. Model M2 decomposes the one-day lagged standardized returns into positive and negative dummy variables to capture a possible sign effect. The inverse leverage effect parameter $\alpha_{2}$ for $Z_{t-1}^{+}$ becomes statistically significant in the first and last sub-period ( $\mathrm{S} 1$ and $\mathrm{S} 4$ ), but not in the turbulent second and third sub-periods (S2 and S3). These latter results imply that the inverse leverage effect is not significant during periods of economic turmoil. In addition, the positive dummy variable remains significant contrary to the negative dummy variable, which means that only a higher oil price induces a higher implied volatility. To what extent can we explain this singular feature? A possible explanation is that if oil prices are driven by the supply-side of the market, the risk is expressed by a decrease of the price since this would affect negatively the revenues of oil-exporting countries. In that case, we expect the volatility to increase after a price decrease. As a consequence, this would manifest itself as a leverage effect much like on equity markets. On the opposite side, if oil prices are driven by the demand-side of the market, the risk increases when the price increases since this would affect negatively the expenses of oil-importing countries. Therefore, the volatility would increase consequently to a price increase. As a consequence, this would manifest itself as an inverse leverage effect (for a more detailed analysis of the supply and demand fundamentals on the crude oil market, in the light of geopolitical events, see Chevillon and Rifflart (2009)).

Table 3 displays the results for any type of feedback effects with models M3 and M4. Previous literature did not document this effect because it does not appear most of the time. For instance, in the model M3, the parameter $\alpha_{2}$ for $\Delta \log O V X_{t-1}$ is significant at the $10 \%$ level during the full period. However, precaution requires looking at the sub-periods and more particularly at the crisis period (S3). Indeed, this sub-period is represented in Figure 1 by a gray rectangle. It can be seen that it corresponds roughly to the financial crisis and the subsequent economic recession. More precisely, S3 (October 3, 2008 - April 15, 2009) begins two weeks after the Lehman Brothers bankruptcy and terminates six weeks before the end of the recession as defined by the NBER business cycle dating committee ${ }^{8}$. During this crisis regime only, an inverse feedback effect (i.e. increasing returns following increasing volatility) is visible as the $\alpha_{3}$ coefficient for $\Delta \log O V X_{t-2}$ is significant at the $5 \%$ level and positive. Hence, model M3 reveals a delayed effect since an inverse feedback effect appears with a two-day lag. This delayed effect might be explained by the fact that volatility should be persistent enough to positively affect oil prices with little delay. In other words, the inverse leverage effect, which occurs with a one-day lag, should be significant enough to induce a regular feedback effect on the very same day, followed by an inverse feedback effect on the day after given the mean-reverting property of implied volatility. Finally, the model M4 displays the decomposition of the one-day lag volatility changes into positive and negative dummy variables. The results show that the $\alpha_{3}$ coefficient for $\Delta \log O V X_{t-1}^{-}$is significant at the $5 \%$ level and negative during S3. This phenomenon is consistent with the regular (not inverse) feedback effect, since a significant decline in volatility induces a subsequent increase in the oil price. Hence, we have uncovered both regular and inverse feedback effects in the WTI crude oil spot price based on the OVX index of implied volatility. It is particularly interesting to notice that this result applies especially during the crisis period spanning October 2008-April 2009.

\footnotetext{
${ }^{8}$ See more information at http://www.nber.org/cycles/recessions.html
} 
The understanding of the lead-lag relation between the crude oil price and the implied volatility index is of importance to modify the risk exposure and consequently the pay-off of any portfolio containing stocks of oil companies. While previous studies have described the inverse leverage effect as a stylized fact on the oil market (using realized or implied volatility), little attention has been paid to the existence of feedback effects during the recent crisis period and their trading implications. For that reason, our study contributes to the extant literaure on the subject by using the OVX index of implied volatility. In line with our research, a trading strategy might hedge any long position on such a portfolio with OVX index futures contracts. The futures contract value directly depends on the OVX value, since it is linear with the oil spot price. Therefore, it will reflect both the inverse leverage effect and the inverse feedback effect particularly during crisis periods. These results can therefore be of interest to traders, fund- and risk-managers alike.

\subsection{Robustness checks}

The sub-periods decomposition can be seen as a first round of robustness checks for the results obtained during the full-period. In addition, and similarly to Hibbert et al. (2008), we have introduced $R V_{t}$ in models $M 1$ to $M 4$ as an additional explanatory variable. These results, not reported here to conserve space but available upon request, did not change qualitatively the conclusions on the leverage and feedback effects reported in Tables 2 and 3.

In what follows, we focus mainly on the $\mathrm{S} 3$ crisis period. First, the predictive power of $R V_{t}$ is confirmed for the models M1 and M2. Indeed, the coefficient estimates for $R V_{t}$ are negative and significant at the $10 \%$ level for model M1, and at the $5 \%$ level for model M2. This result is logical, since implied volatility remains a measure of uncertainty. Suppose that the OPEC cartel takes a decision about the daily production of oil barrels. The uncertainty associated with this decision should increase $\Delta \log O V X_{t}$, but not necessary $R V_{t}$. Once the decision is taken, the uncertainty disappears. If the decision is to increase production, the uncertainty should disappear, which might decrease $\Delta \log O V X_{t}$ while $R V_{t}$ should decline or remains stable. On the contrary, if the cartel decides to cut production, $\Delta \log O V X_{t}$ should decline but $R V_{t}$ might climb. Most of the time, implied volatility and realized volatility are negatively correlated.

\section{Conclusion}

The oil return-volatility relation is widely documented in the financial economics literature. However, few articles explore the economic meaning of the inverse leverage effect, which characterizes an increase in the volatility subsequent to an increase in the oil price. In addition, no previous study has documented the existence of any type of feedback effects (either regular or inverse) for crude oil prices.

This article establishes that the inverse leverage effect is the dominant effect driving the WTI crude oil spot price, with a data sample spanning May 2007-December 2011. This result might reflect the fear for the oil importing countries, mainly western and major emerging countries, to face the risk attached to climbing oil prices. To our best knowledge, this article uncovers for the first time both regular and inverse feedback effects in crude oil prices, which can be observed only during the October 2008-April 2009 crisis period. We argue that the existence of both types of feedback effects is consistent with the mean-reverting property of implied volatility, as the CBOE OVX index is used. 
The main practical application of our work may be stated as follows. The lead-lag relation between the oil price and its volatility is determinant for any type of trading strategy involving oil company stock portfolios, where the risks and pay-offs can be modified by futures and options on the OVX implied volatility index.

\section{References}

[1] Agnolucci, P., 2009. Volatility in crude oil futures: A comparison of the predictive ability of GARCH and implied volatility models. Energy Economics 31, 316-321.

[2] Andersen, T.G., Bollerslev, T., Diebold, F.X., Labys, P., 2003. Modeling and forecasting realized volatility. Econometrica 71, 579-625.

[3] Bekaert G. and G. Wu, 2000. Asymmetric volatility and risk in equity markets. Review of Financial Studies 13 , $1-42$.

[4] Bai, J., Perron, P., 1997. Estimation of a change point in multiple regression models. Review of Economics and Statistics 79, 551-563.

[5] Bai, J., Perron, P., 1998. Estimating and testing linear models with multiple structural changes. Econometrica 66, 47-78.

[6] Bai, J., Perron, P., 2003. Computation and analysis of multiple structural change models. Journal of Applied Econometrics 18, 1-22.

[7] Black, F., 1976. Studies in stock price volatility changes, American Statistical Association, Proceedings of the Business and Economic Statistics Section, 177-181.

[8] Bollerslev, T. and H. Zhou, 2006. Volatility puzzles: A unified framework for gauging return-volatility regressions. Journal of Econometrics 131, 123-150.

[9] Campbell, J. Y. and L. Hentchel, 1992. No news is good news: An asymmetric model of changing volatility in stock returns. Journal of Financial Economics 31, 281-318.

[10] Chang, K.L., 2012. Volatility regimes, asymmetric basis effects and forecasting performance: An empirical investigation of the WTI crude oil futures market. Energy Economics 34, 294-306.

[11] Chevillon, G., Rifflart, C. 2009. Physical market determinants of the price of crude oil and the market premium. Energy Economics 31, 537-549.

[12] Christie, A., 1982. The stochastic behavior of common stock variances - value, leverage, and interest rate effects. Journal of Financial Economic Theory 10, 407-432.

[13] Fleming, J., Ostdiek, B., Whaley, R. 1995. Predicting stock market volatility: A new measure. Journal of Futures Markets 15, 265-302.

[14] Geman, H., Shih, Y.F., 2009. Modeling Commodity Prices Under the CEV Model. Journal of Alternative Investments $11,65-84$.

[15] Hibbert A. M., Daigler R. T. and B. Dupoyet, 2008. A behavioral explanation for the negative asymmetric return-volatility relation. Journal of Banking and Finance 32, 2254-2266.

[16] Konstantinidi, E., Skiadopoulos, G., Tzagkaraki, E., 2008. Can the evolution of implied volatility be forecasted? Evidence from European and US implied volatility indices. Journal of Banking \& Finance 32, 2401-2411.

[17] Lanza, A., Manera, M., McAleer, M., 2006. Modeling dynamic conditional correlations in WTI oil forward and futures returns. Finance Research Letters 3, 114-132.

[18] Larsson, K., Nossman, M., 2011. Jumps and stochastic volatility in oil prices: Time series evidence. Energy Economics 33, 504-514.

[19] Zeileis, A., Kleiber, C., 2005. Validating multiple structural change modelsa case study. Journal of Applied Econometrics 20, 685-690. 
Figure 1: Time series of WTI raw prices and OVX index

Figure 1 displays the raw prices of WTI, and the CBOE OVX Index for Implied Volatility (OVX) from May, 102007 to December, 302011.

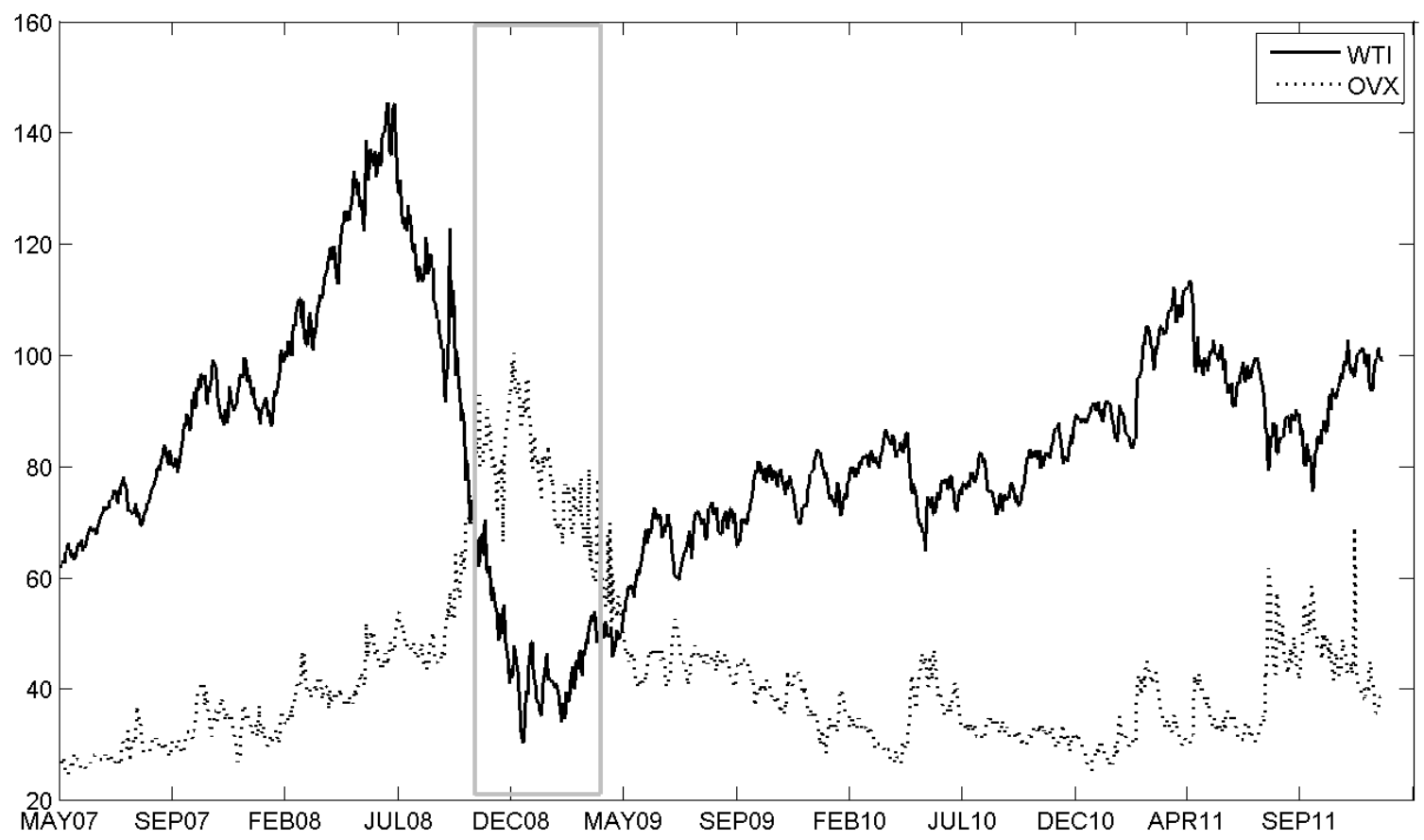


Figure 2: Breakpoints detection: RSS and BIC criteria for models up to 37 breaks

Figure 2 displays the number of breaks according to Bai and Perron's methodology based on the corresponding values of the BIC and the RSS. Results are shown for OVX .

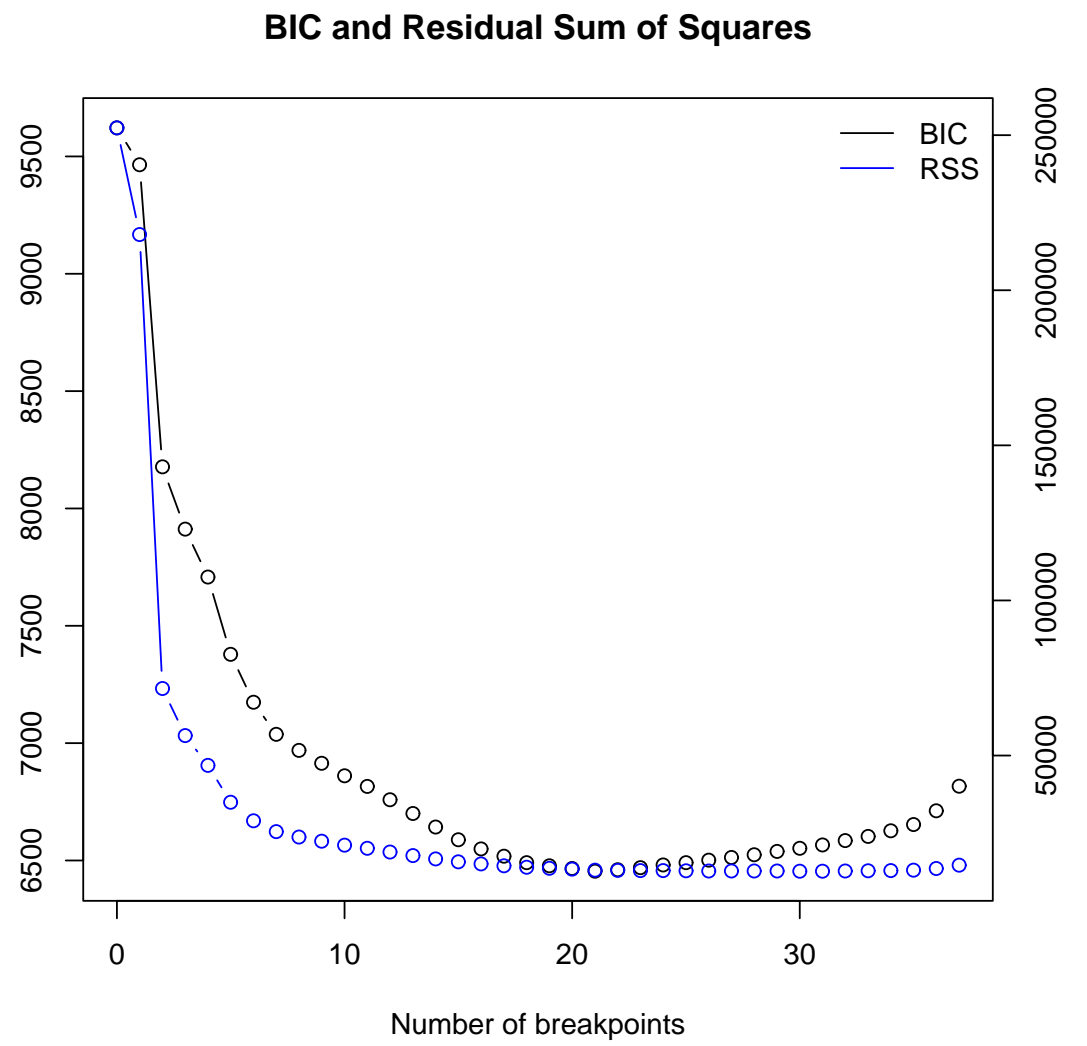


Table 1: Descriptive statistics

Table 1 presents the descriptive statistics for the raw prices of WTI, the corresponding standardized daily log-returns $\left(Z_{t}\right)$, the CBOE OVX Index for Implied Volatility $\left(\Delta \log O V X_{t}\right)$, and the historical GARCH volatility $\left(\sigma_{t}^{2}\right)$ from May 10, 2007 to December 30, 2011. The realized volatility is denoted RV, and goes from May 10, 2007 to January 15, 2010. The historical volatility model is an $\operatorname{ARMA}(1,1)+\operatorname{GARCH}(1,1)$. The last column reports the parameter estimates of Eq.(1)-(4).

\begin{tabular}{cccccccc}
\hline \multicolumn{1}{c}{$Z_{t}$} & $\Delta \log O V I_{t}$ & $\sigma_{t}^{2}$ & $R V_{t}$ & & $\sigma_{t}^{2}$ \\
\hline Mean & 83.3461 & 0.0004 & 42.2020 & 41.1640 & 0.0005 & $\mu$ & 0.00018 \\
Median & 81.8700 & 0.0010 & 38.7000 & 34.37640 & 0.0003 & $\phi_{1}$ & $0.8790^{* * *}$ \\
Max. & 145.3100 & 0.1641 & 100.4200 & 120.8378 & 0.0040 & $\theta_{1}$ & $-0.9015^{* * *}$ \\
Min. & 30.2800 & -0.1282 & 24.6700 & 17.4440 & 0.0001 & $\omega$ & $7.30 \mathrm{e}-07^{* * *}$ \\
Std. Dev. & 21.0028 & 0.0282 & 14.6933 & 21.4723 & 0.0006 & $\alpha$ & $0.0858^{* * *}$ \\
Skew. & 0.2015 & 0.0235 & 1.7123 & 1.8963 & 2.4333 & $\beta$ & $0.9221^{* * *}$ \\
Kurt. & 3.3692 & 7.4663 & 5.6653 & 5.7442 & 9.5824 & Log - likelihood & 18840.82 \\
JB & 14.58232 & 973.4039 & 918.8976 & 1069.296 & 1895.925 & & \\
Prob(JB) & 0.0006 & 0.0000 & 0.0000 & 0.0000 & 0.0000 & & \\
N & 1172 & 1171 & 1171 & 1171 & 678 & & \\
\hline
\end{tabular}

Note: Max. stands for Maximum, Min. for Minimum, Std. Dev. for Standard Deviation, Skew. for Skewness, Kurt. for Kurtosis, JB for the Jarque-Bera statistic, $\operatorname{Prob}(\mathrm{JB})$ for the $p$-value of the Jarque-Bera statistic, and $\mathrm{N}$ for the number of daily observations. 
Table 2: Leverage effects: Estimation results

Table 2 presents the estimation results for the leverage effects. The dependent variable is the current implied volatility log-changes $\Delta$ log $O V X_{t}$.

\begin{tabular}{|c|c|c|c|c|c|c|c|c|c|c|}
\hline Leverage & Period & Adj. $\mathbf{R}^{2}(\%)$ & Intercept & $Z_{t}$ & $Z_{t-1}$ & $\left|Z_{t}\right|$ & $\operatorname{AR}(1)$ & MA(1) & $Z_{t-1}^{+}$ & $Z_{t-1}^{-}$ \\
\hline \multirow[t]{5}{*}{$M 1$} & Full & 21.4 & $\begin{array}{c}-0.0200^{* * *} \\
(0.0017)\end{array}$ & $\begin{array}{c}-0.0137^{* * *} \\
(0.0013)\end{array}$ & $\begin{array}{c}0.0043^{* * *} \\
(0.0013)\end{array}$ & $\begin{array}{c}0.0265^{* * *} \\
(0.0020)\end{array}$ & $\begin{array}{c}0.5728^{* * *} \\
(0.0645)\end{array}$ & $\begin{array}{c}-0.7796^{* * *} \\
(0.0494)\end{array}$ & & \\
\hline & S1 & 6.0 & $\begin{array}{c}-0.0106^{* *} \\
(0.0049)\end{array}$ & $\begin{array}{l}-0.0048^{*} \\
(0.0029)\end{array}$ & $\begin{array}{c}0.0098^{* * *} \\
(0.0029)\end{array}$ & $\begin{array}{c}0.0141^{\text {*** }} \\
(0.0049)\end{array}$ & $\begin{array}{l}-0.5075 \\
(1.2011)\end{array}$ & $\begin{array}{c}0.4997 \\
(1.2095)\end{array}$ & & \\
\hline & S2 & 25.1 & $\begin{array}{c}-0.0198^{* * *} \\
(0.0030)\end{array}$ & $\begin{array}{c}0.0015 \\
(0.0026)\end{array}$ & $\begin{array}{c}0.0008 \\
(0.0026)\end{array}$ & $\begin{array}{c}0.0265^{* * *} \\
(0.0036)\end{array}$ & $\begin{array}{c}0.6320^{* * *} \\
(0.0662)\end{array}$ & $\begin{array}{c}-0.9925^{* * *} \\
(0.0096)\end{array}$ & & \\
\hline & S3 & 18.6 & $\begin{array}{c}-0.0202^{* * *} \\
(0.0072)\end{array}$ & $\begin{array}{c}-0.0150^{* * *} \\
(0.0055)\end{array}$ & $\begin{array}{c}0.0022 \\
(0.0055)\end{array}$ & $\begin{array}{c}0.0245^{\text {*** }} \\
(0.0086)\end{array}$ & $\begin{array}{c}0.1805 \\
(0.1971)\end{array}$ & $\begin{array}{c}-0.5864^{* * *} \\
(0.1604)\end{array}$ & & \\
\hline & $\mathrm{S} 4$ & 33.4 & $\begin{array}{c}-0.0192^{* * *} \\
(0.0025)\end{array}$ & $\begin{array}{c}-0.0196^{* * *} \\
(0.0017)\end{array}$ & $\begin{array}{c}0.0024 \\
(0.0017)\end{array}$ & $\begin{array}{c}0.0250^{* * *} \\
(0.0025)\end{array}$ & $\begin{array}{c}-0.7712^{* * *} \\
(0.0492)\end{array}$ & $\begin{array}{c}0.7280^{* * *} \\
(0.0590)\end{array}$ & & \\
\hline \multirow[t]{5}{*}{ M2 } & Full & 21.5 & $\begin{array}{c}-0.0220^{* * *} \\
(0.0021)\end{array}$ & $\begin{array}{c}-0.0136^{* * *} \\
(0.0013)\end{array}$ & & $\begin{array}{c}0.0257^{* * *} \\
(0.0021)\end{array}$ & $\begin{array}{c}0.5840^{* * *} \\
(0.0624)\end{array}$ & $\begin{array}{c}-0.7905^{* * *} \\
(0.0472)\end{array}$ & $\begin{array}{c}0.0077^{* * *} \\
(0.0025)\end{array}$ & $\begin{array}{c}0.0011 \\
(0.0024)\end{array}$ \\
\hline & S1 & 6.3 & $\begin{array}{c}-0.0155^{* *} \\
(0.0065)\end{array}$ & $\begin{array}{c}-0.0047^{*} \\
(0.0029)\end{array}$ & & $\begin{array}{c}0.0145^{\text {*** }} \\
(0.0049)\end{array}$ & $\begin{array}{l}-0.4176 \\
(1.4150)\end{array}$ & $\begin{array}{c}0.4176 \\
(1.4175)\end{array}$ & $\begin{array}{c}0.0150^{* * *} \\
(0.0052)\end{array}$ & $\begin{array}{c}0.0032 \\
(0.0062)\end{array}$ \\
\hline & S2 & 24.6 & $\begin{array}{c}-0.0199^{* * *} \\
(0.0034)\end{array}$ & $\begin{array}{c}0.0015 \\
(0.0026)\end{array}$ & & $\begin{array}{c}0.0263^{* * *} \\
(0.0045)\end{array}$ & $\begin{array}{c}0.6318^{* * *} \\
(0.0666)\end{array}$ & $\begin{array}{c}-0.9924^{* * *} \\
(0.0100)\end{array}$ & $\begin{array}{c}0.0010 \\
(0.0052)\end{array}$ & $\begin{array}{c}0.0005 \\
(0.0053)\end{array}$ \\
\hline & S3 & 18.1 & $\begin{array}{c}-0.0224^{* * *} \\
(0.0086)\end{array}$ & $\begin{array}{c}-0.0151^{* * *} \\
(0.0055)\end{array}$ & & $\begin{array}{l}0.0229^{* *} \\
(0.0092)\end{array}$ & $\begin{array}{c}0.1602 \\
(0.2000)\end{array}$ & $\begin{array}{c}-0.5704^{* * *} \\
(0.1647)\end{array}$ & $\begin{array}{c}0.0067 \\
(0.0108)\end{array}$ & $\begin{array}{l}-0.0021 \\
(0.0106)\end{array}$ \\
\hline & $\mathrm{S} 4$ & 33.4 & $\begin{array}{c}-0.0214^{* * *} \\
(0.0031)\end{array}$ & $\begin{array}{c}-0.0197^{* * *} \\
(0.0017)\end{array}$ & & $\begin{array}{c}0.0248^{* * *} \\
(0.0025)\end{array}$ & $\begin{array}{c}-0.7728^{* * *} \\
(0.0489)\end{array}$ & $\begin{array}{c}0.7287^{* * *} \\
(0.0587)\end{array}$ & $\begin{array}{l}0.0058^{*} \\
(0.0032)\end{array}$ & $\begin{array}{l}-0.0004 \\
(0.0029)\end{array}$ \\
\hline
\end{tabular}

Note: Adj. $\mathrm{R}^{2}(\%)$ stands for the Adjusted R-squared in percentage. Full stands for Full period. S1 to S4 stand for the sub-periods 1 to $4 . * * *, * *, *$ stand for statistical significance at the $1 \%$,

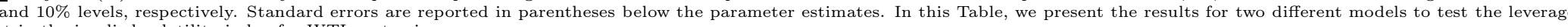
(fect in the implied volatility index for WTI spot prices:

$M 1: \Delta \log O V X_{t}=\alpha_{0}+\alpha_{1} Z_{t}+\alpha_{2} Z_{t-1}+\alpha_{3} \Delta \log O V X_{t-1}+\alpha_{4}\left|Z_{t}\right|+\alpha_{5} \epsilon_{t-1}+\epsilon_{t}$

M2: $\Delta \log O V X_{t}=\alpha_{0}+\alpha_{1} Z_{t}+\alpha_{2} Z_{t-1}^{+}+\alpha_{3} Z_{t-1}^{-}+\alpha_{4} \Delta \log O V X_{t-1}+\alpha_{5}\left|Z_{t}\right|+\alpha_{6} \epsilon_{t-1}+\epsilon_{t}$ 
Table 3: Feedback effects: Estimation results

Table 3 presents the estimation results for the feedback effects. The dependent variable is the standardized daily log-returns $Z_{t}$.

\begin{tabular}{|c|c|c|c|c|c|c|c|c|c|c|}
\hline Feedback & Period & Adj. $\mathbf{R}^{2}(\%)$ & Intercept & $\Delta \log O V X_{t}$ & $\Delta \log O V X_{t-1}$ & $\Delta \log O V X_{t-2}$ & $\Delta \log O V X_{t-3}$ & $\left|\Delta \log O V X_{t}\right|$ & $\Delta \log O V X_{t-1}^{+}$ & $\Delta \log O V X_{t-1}^{-}$ \\
\hline \multirow[t]{8}{*}{ M3 } & Full & 7.8 & $\begin{array}{l}0.0669^{*} \\
(0.0402)\end{array}$ & $-5.2979^{* * *}$ & $-0.9222^{*}$ & -0.3121 & 0.1299 & -1.0038 & & \\
\hline & S1 & 2.3 & $\begin{array}{c}(0.0402) \\
0.2767^{* * *}\end{array}$ & $\begin{array}{l}(1.0203) \\
-1.3919\end{array}$ & $\begin{array}{l}(0.5596) \\
-1.7013\end{array}$ & $\begin{array}{c}(0.4871) \\
0.6050\end{array}$ & $\begin{array}{l}(0.4303) \\
-1.0048\end{array}$ & $\begin{array}{l}(1.0893) \\
-3.2939\end{array}$ & & \\
\hline & & & $(0.0942)$ & $(1.9502)$ & $(1.7341)$ & $(1.4559)$ & (1.6339) & (2.4678) & & \\
\hline & S2 & 1.78 & 0.0272 & 1.2250 & 0.9178 & -2.7475 & -0.1173 & -0.4277 & & \\
\hline & & & $(0.1167)$ & $(3.4588)$ & $(2.0503)$ & $(2.3849)$ & (2.1018) & $(3.4876)$ & & \\
\hline & S3 & 6.5 & -0.1203 & $-3.7121^{* *}$ & -0.8381 & $2.8191^{* *}$ & 0.8970 & 0.1637 & & \\
\hline & & & $(0.1180)$ & $(1.5009)$ & $(1.5015)$ & $(1.2250)$ & $(1.0456)$ & (1.7441) & & \\
\hline & S4 & 16.1 & 0.0436 & $-7.4010^{* * *}$ & -1.0493 & $\begin{array}{l}-0.7309 \\
(0.5771)\end{array}$ & 0.1110 & -0.8221 & & \\
\hline \multirow[t]{10}{*}{ M4 } & Full & 7.8 & $0.0723^{*}$ & $-5.3174^{* * *}$ & & & & -0.9803 & -0.9809 & -0.6782 \\
\hline & & & $(0.0420)$ & $(0.5763)$ & & & & $(0.7730)$ & $(0.8717)$ & (1.0194) \\
\hline & S1 & 2.1 & $0.2496^{* *}$ & -1.2649 & & & & -3.4259 & -0.6921 & -2.9461 \\
\hline & & & $(0.1178)$ & (1.7443) & & & & (2.5774) & $(2.6373)$ & $(3.5263)$ \\
\hline & S2 & 2.1 & 0.0415 & 1.5339 & & & & -0.8636 & 1.5320 & 2.6092 \\
\hline & & & $(0.1461)$ & $(2.4346)$ & & & & (3.2170) & (3.3948) & $(4.2802)$ \\
\hline & S3 & 6.3 & $-0.2152^{*}$ & $-3.6955^{* * *}$ & & & & -0.6570 & 1.0351 & $-4.7716^{* *}$ \\
\hline & & & $(0.1255)$ & $(1.3066)$ & & & & $(1.7423)$ & $(2.1596)$ & $(2.1970)$ \\
\hline & S4 & 16.1 & 0.0673 & $-7.5475^{* * *}$ & & & & -0.5823 & $-1.7143^{*}$ & 0.1326 \\
\hline & & & $(0.0505)$ & $(0.6953)$ & & & & $(0.9208)$ & $(1.0349)$ & $(1.2160)$ \\
\hline
\end{tabular}
Note: Adj. $\mathrm{R}^{2}(\%)$ stands for the Adjusted $\mathrm{R}$-squared in percentage. Full stands for Full period. $\mathrm{S} 1$ to $\mathrm{S} 4$ stand for the sub-periods 1 to $4 . * * *, * *, *$ stand for statistical significance at the $1 \%$,
$5 \%$ and $10 \%$ levels, respectively. Standard errors are reported in parentheses below the parameter estimates. In this Table, we present the results for two different models to test the feedback effect in the standardized returns of WTI spot prices:

$M 3: Z_{t}=\alpha_{0}+\alpha_{1} \Delta \log O V X_{t}+\alpha_{2} \Delta \log O V X_{t-1}+\alpha_{3} \Delta \log O V X_{t-2}+\alpha_{4} \Delta \log O V X_{t-3}+\alpha_{5}\left|\Delta \log O V X_{t}\right|+\epsilon_{t}$ 